\title{
Chemotherapy of drug-resistant malaria
}

\author{
KEVIN C KAIN MD
}

KC KAIN. Chemotherapy of drug-resistant malaria. Can J Infect Dis 1996;7(1):25-33.

OBJECTIVE: To review the impact of drug-resistant malaria on current management of plasmodial infections. DATA SOURCES: A MEDLINE search of the English-language medical literature from 1985 to 1995; bibliographies of selected papers; international malaria advisory experts.

DATA SYNTHESIS: Combinations of artemisinin derivatives and mefloquine or atovaquone plus proguanil appear to be the most active drug regimens against multidrug-resistant falciparum malaria from Southeast Asia. The optimal therapy for chloroquine-resistant Plasmodium vivax is unknown, but recent data indicate that halofantrine or chloroquine plus high doses of primaquine are efficacious.

CONCLUSIONS: The incidence of drug-resistant malaria continues to increase at a rate that exceeds new drug development. Ultimately the control of malaria will require more creative approaches than just the development of additional inhibitory drugs. These might include the identification of biochemical pathways unique to the parasite (such as drug efflux and heme polymerization), making it possible to design new classes of antimalarial agents that are selectively toxic to the parasite; methods to block parasite development in the mosquito vector; and multistage vaccines against asexual and sexual stages to block both the pathophysiology and the transmission of disease.

Key Words: Drug-resistant malaria, Plasmodium falciparum, Plasmodium vivax

\section{Traitement pharmacologique du paludisme réfractaire}

OBJECTIF : Passer en revue l'impact du paludisme réfractaire aux médicaments sur le traitement courant des infections plasmodiales.

SOURCES DES DONNÉES : Une interrogation du Réseau MEDLINE sur la littérature médicale de langue anglaise publiée entre 1985 et 1995, bibliographies d'articles sélectionnés, experts-conseils internationnaux sur le paludisme. SYNTHÈSE DES DONNÉES : Les associations de dérivés d'artémisinine, de méfloquine ou d'atovaquone plus proguanil semblent être les schémas médicamenteux les plus efficaces contre le paludisme à falciparum résistant à plusieurs médicaments, en provenance de l'Asie du sud-est. Le traitement optimal dans les cas de Plasmodium vivax résistant à la chloroquine est inconnu, mais selon des données récentes, l'halofantrine ou la chloroquine avec dose élevée de primaquine sont efficaces.

CONCLUSIONS : L'incidence du paludisme résistant aux médicaments continue d'augmenter à un taux qui excède la vitesse de mise au point de nouveaux médicaments. Éventuellement, la maîtrise du paludisme exigera des approches plus créatrices que le simple développement d'autres médicaments inhibiteurs. Parmi ces approches, l'identification des voies biochimiques empruntées par ce parasite (comme l'efflux des médicaments et la polymérisation de l'hème) rendra possible la conception de nouvelles classes d'agents antipaludéens sélectivement toxiques à l'endroit du parasite, de méthodes en vue de bloquer le développement du parasite dans le vecteur même et de vaccins à plusieurs stades d'action contre les stades asexuels et sexuels en vue de bloquer la physiopathologie aussi bien que la transmission de la maladie.

Tropical Disease Unit, Division of Infectious Diseases, Department of Medicine, University of Toronto and The Toronto Hospital, Toronto, Ontario

Correspondence: Dr KC Kain, Room EN G224, Tropical Disease Unit, The Toronto Hospital, 200 Elizabeth Street, Toronto, Ontario M5G 2C4.

Telephone 416-340-3535, fax 416-595-5826, e-mail kkain@torhosp.toronto.on.ca

Received for publication October 15, 1995. Accepted November 14, 1995 
$\mathrm{T}$ he incidence of malaria has increased over the past two decades and it is estimated that 270 million patients are infected annually, resulting in 1.5 to 3.5 million deaths (1). This resurgence is, in large part, attributable to the appearance and rapid spread of falciparum malaria resistant to antimalarial drugs (2). Globally, the proportion of cases caused by Plasmodium falciparum has increased from 15\% in the early 1970 s to at least $40 \%$ of all reported cases in 1989 (3). In addition to drug resistance, several other factors, including large scale uncontrolled population movements and ecological disturbances, have contributed to the worsening malaria problem. Environmental change brought about by development has created conditions suitable for malaria transmission $(4,5)$. Changes in terrestrial ecosystems and global warming have recently been implicated in increases in malaria incidence of $400 \%$ and $564 \%$ in South America and Rwanda, respectively (4-7).

Malaria is a problem not only of the tropics and the developing world. Imported malaria is an escalating problem worldwide $(8,9)$. It is estimated that as many as 30,000 North American and European travellers contract malaria annually (10) including increasing numbers of drug-resistant infections $(8,9)$. The number of cases of falciparum malaria diagnosed in Britain increased 400\% from 1977 to 1991 (8). Rates of imported falciparum malaria have increased four- to sixfold in two centres in Canada $(11,12)$. The number of Canadians travelling overseas has doubled in the past decade to more than 3 million/year, many to or through malaria endemic areas. The number and severity of malaria cases imported into Canada are likely to increase in the future.
Approximately $90 \%$ of travellers who acquire malaria will not develop symptoms until after returning home (13). Progression from disease-free state to cerebral malaria and death can occur in as little as 36 to $48 \mathrm{~h}$ (1). The mortality of severe malaria is $30 \%$ or more, even for previously healthy adults treated in modern intensive care units. Therefore, preventing imported malaria deaths will require prompt recognition of cases and an accurate species diagnosis. However, recognition of malaria by physicians and accurate species diagnosis by laboratories remain important problems in nonendemic areas, resulting in potential delays in treatment and errors in management (13-15).

The outlook for new drugs to prevent and treat malaria is relatively bleak (16). Rates of resistance to mefloquine and halofantrine, the latest antimalarial drugs approved by Health and Welfare Canada and the Food and Drug Administration in the United States, now approach 50\% in regions of Thailand (16). Resistance to both agents is already appearing in Africa $(17,18)$. Moreover, recent susceptibility data from Thailand indicate that there has been a steady decrease in response of $P$ falciparum isolates to quinine, indicating the impending loss of an essential therapy for severe and complicated malaria (19).

This review focuses on the changing management of plasmodial infections. It outlines new drugs and drug combinations for the treatment of drug-resistant vivax and falciparum malaria (Tables 1 and 2), but it does not discuss prevention of malaria or other clinical aspects of managing severe malaria. The reader is referred to the review by Warrell et al (15) for additional treatment issues.

TABLE 1

Treatment of malaria

\begin{tabular}{|c|c|c|c|}
\hline Parasite & Geographic distribution & Treatment of choice & Alternatives \\
\hline $\begin{array}{l}\text { Plasmodium vivax, } \\
\text { Plasmodium malariae }\end{array}$ & $\begin{array}{l}\text { Worldwide in malaria-endemic } \\
\text { areas }\end{array}$ & $\begin{array}{l}\text { Chloroquine followed by } \\
\text { primaquine* for } P \text { vivax and } \\
\text { Plasmodium ovale }\end{array}$ & (see below) \\
\hline P ovale & $\begin{array}{l}\text { Primarily West Africa, but also } \\
\text { Oceania }\end{array}$ & & \\
\hline $\begin{array}{l}\text { Chloroquine-resistant } \\
P \text { vivax }\end{array}$ & Oceania, Brazil, Myanmar & $\begin{array}{l}\text { Chloroquine plus high dose } \\
\text { primaquine }{ }^{\dagger} \text {, halofantrine }\end{array}$ & $\begin{array}{l}\text { Quinine plus doxycycline; } \\
\text { mefloquine }\end{array}$ \\
\hline $\begin{array}{l}\text { Primaquine-resistant } \\
P \text { vivax }\end{array}$ & $\begin{array}{l}\text { Oceania, Southeast Asia, } \\
\text { Colombia, India, Africa }\end{array}$ & Double dose primaquine ${ }^{*^{\ddagger}}$ & - \\
\hline $\begin{array}{l}\text { Choroquine-sensitive } \\
\text { Plasmodium falciparum }\end{array}$ & $\begin{array}{l}\text { Caribbean, Central America } \\
\text { (above Panama), North Africa, } \\
\text { Middle East }\end{array}$ & Chloroquine & (see below) \\
\hline $\begin{array}{l}\text { Chloroquine-resistant } \\
\text { P falciparum }\end{array}$ & $\begin{array}{l}\text { All other malaria-endemic } \\
\text { areas }\end{array}$ & $\begin{array}{l}\text { Quinine plus tetracycline OR } \\
\text { plus pyrimethamine- } \\
\text { sulfadoxine** OR }^{*} \text { plus clindamycin }^{++}\end{array}$ & $\begin{array}{l}\text { Mefloquine }{ }^{\S} \text {; halofantrine; } \\
\text { artesunate plus mefloquine }{ }^{\S} ; \\
\text { other qinghaosu derivatives } \\
\text { atovaquone plus proguanil }\end{array}$ \\
\hline
\end{tabular}

Adapted from reference 60. *Patients should be screened for G-6-PD deficiency before primaquine treatment. Primaquine should not be used during pregnancy; ${ }^{+}$Chloroquine alone is no longer adequate to treat $P$ vivax acquired in Papua New Guinea and Irian Jaya. Elsewhere chloroquine remains drug of choice. For areas with cholorquine-resistant $P$ vivax, chloroquine plus primaquine $2.5 \mathrm{mg} / \mathrm{kg}$ over $48 \mathrm{~h}$ OR halofantrine $8 \mathrm{mg} / \mathrm{kg}$ every $6 \mathrm{~h}$ divided into three doses are effective; ${ }^{\ddagger} 22.5$ to $30 \mathrm{mg}$ base/day for 14 days OR $6 \mathrm{mg} / \mathrm{kg}$ total dose; ${ }^{\S}$ Combination artesunate plus mefloquine OR mefloquine plus tetracycline are used to treat multidrug-resistant falciparum malaria in Southeast Asia; "Including artemisinin, artemether, arteether combined with tetracycline or mefloquine; ${ }^{* *}$ Resistance to pyrimethamine-sulfadoxine is $60 \%$ or greater in Southeast Asia and Amazonia in Brazil; ${ }^{+t}$ In patients unable to take tetracyclines or pyrimethamine-sulfadoxine 
TABLE 2

Chemotherapeutic agents for malaria

\begin{tabular}{|c|c|c|c|}
\hline Agent & Dose (adults) & $\begin{array}{l}\text { Duration course } \\
\text { (days) }\end{array}$ & Adverse effects \\
\hline $\begin{array}{l}\text { Quinine dihydrochloride } \\
\text { (iv) }\end{array}$ & $\begin{array}{l}\text { In severe malaria only: } 16.7 \mathrm{mg} \text { (base)/kg } \\
\text { loading dose over } 4 \mathrm{~h} \\
\text { followed by } 8.3 \mathrm{mg} \text { (base)/kg every } \\
8 \mathrm{~h} \text { given over } 4 \mathrm{~h} *\end{array}$ & $--^{+}$ & $\begin{array}{l}\text { Cardiac dysrhythmia, cinchonism } \\
\text { (tinnitus, deafness, gastrointestinal dis- } \\
\text { turbance, dysphoria), } \\
\text { hypoglycemia }\end{array}$ \\
\hline $\begin{array}{l}\text { Quinidine gluconate } \\
\text { (iv) }\end{array}$ & $\begin{array}{l}\text { In severe malaria only: } 6.2 \mathrm{mg} \text { (base)/kg } \\
\text { loading dose ( } 600 \mathrm{mg} \text { maximum) slowly } \\
\text { over } 1 \text { to } 2 \mathrm{~h} \text { followed by } 0.0125 \mathrm{mg} \\
\text { (base) } / \mathrm{kg} / \mathrm{min} \text { for } 72 \mathrm{~h} \text { maximum }{ }^{*^{\ddagger}}\end{array}$ & $--^{+}$ & (as above) \\
\hline Quinine sulphate (po) & 600 mg every $8 \mathrm{~h}$ & $3-7^{\S}$ & Cinchonism, hypoglycemia \\
\hline Tetracycline (po) & $250 \mathrm{mg}$ qid & 7 & $\begin{array}{l}\text { Gastrointestinal disturbance, } \\
\text { photosensitivity, contraindicated in } \\
\text { pregnant women and children }\end{array}$ \\
\hline $\begin{array}{l}\text { Pyrimethamine- } \\
\text { sulfadoxine (po) }\end{array}$ & 3 tablets & 1 & $\begin{array}{l}\text { Rash; rarely erythema multiforme }{ }^{\pi}, \\
\text { Stevens-Johnson syndrome }{ }^{\pi}, \\
\text { hepatitis, serum sickness, } \\
\text { agranulocytosis (< } 8 \text { years old) }\end{array}$ \\
\hline Clindamycin (po/iv) & $450-900 \mathrm{mg}$ tid & 5 & Gastrointestinal disturbance \\
\hline Mefloquine (po) & $1250^{* *} \mathrm{mg}(15-25 \mathrm{mg} / \mathrm{kg})$ & 1 & $\begin{array}{l}\text { Dizziness, gastrointestinal disturbances, } \\
\text { headache, sleep disturbance; rarely } \\
\text { confusion, psychosis }^{++} \text {, convulsions }{ }^{+\dagger}\end{array}$ \\
\hline Halofantrine (po) & $500 \mathrm{mg}$ every $6 \mathrm{~h}$ in 3 doses & $\begin{array}{l}\text { Day } 1 \text { and } \\
\text { day } 7\end{array}$ & $\begin{array}{l}\text { Cardiac dysrhythmia (prolonged QT), } \\
\text { pruritis, rash, diarrhea }\end{array}$ \\
\hline Artesunate (po/iv/im) & $100 \mathrm{mg}$ then $50 \mathrm{mg}$ every $12 \mathrm{~h}$ & $5-7$ & $\begin{array}{l}\text { Gastrointestinal disturbance, headache, } \\
\text { dizziness, rash, fever, transient first- } \\
\text { degree heart block, liver enzyme ele- } \\
\text { vations }\end{array}$ \\
\hline Artemether (im) & $3.2-4 \mathrm{mg} / \mathrm{kg}$ then $1.6-2 \mathrm{mg} / \mathrm{kg}$ every $24 \mathrm{~h}$ & $5-7$ & (as above) \\
\hline Artemisinin (suppositories) & $2800 \mathrm{mg}$ total dose & Over 3 days & (as above), rectal irritation \\
\hline Chloroquine (po) & $\begin{array}{l}600 \mathrm{mg} \text { base, then } 300 \mathrm{mg} \text { base } 6 \mathrm{~h} \text { later, } \\
\text { then } 300 \mathrm{mg} \text { base at } 24 \text { and } 48 \mathrm{~h}\end{array}$ & 3 & $\begin{array}{l}\text { Pruritus, vomiting, headache; rarely re- } \\
\text { tinopathy, psychosis, seizures, rash, } \\
\text { alopecia, agranulocytosis }\end{array}$ \\
\hline Primaquine (po) & 15 mg base/day ${ }^{\neq \neq}$ & 14 & $\begin{array}{l}\text { Hemolytic anemia in G-6-PD defi- } \\
\text { ciency, gastrointestinal disturbances; } \\
\text { methemoglobinemia }\end{array}$ \\
\hline
\end{tabular}

*Quinidine may be more active than quinine. Loading dose must be omitted in patients who have recently received quinine or mefloquine. In patients requiring more than $48 \mathrm{~h}$ of parenteral treatment, reduce the maintenance dose of quinine or quinidine by $1 / 3$ to $1 / 2{ }^{\dagger}{ }^{+}$Oral quinine should be substituted as soon as possible; ${ }^{\ddagger}$ Electrocardiographic monitoring is necessary to detect arrhythmias; ${ }^{\S}$ Oral administration is the route of choice except in patients with severe malaria. Infections from Southeast Asia require a total of seven days of therapy; "Risk of severe cutaneous adverse reaction with single treatment dose of pyrimethamine-sulfadoxine is estimated to be 0.1 per million (reference 61); **Frequently given as a divided dose of $15 \mathrm{mg} / \mathrm{kg}$ (approximately $750 \mathrm{mg}$ ) followed by $10 \mathrm{mg} / \mathrm{kg}$ (approximately $500 \mathrm{mg}$ ) $6 \mathrm{~h} \mathrm{later;}{ }^{+\dagger}$ Risk of psychosis or seizure with treatment dose is estimated to be 1/215 to 1/1700 users. Contraindicated in patients with history of neuropsychiatric disorders; ${ }^{\neq \pm}$Doses are increased to 22.5 to $30 \mathrm{mg}$ base/day OR a total of $6 \mathrm{mg} / \mathrm{kg}$ for primaquine-resistant Plasmodium vivax. G-6-PD Glucose-6-phosphate dehydrogenase; im Intramuscular; iv Intravenous; po By mouth

malaria or other clinical aspects of managing severe malaria. The reader is referred to the review by Warrell et al (15) for additional treatment issues.

\section{EPIDEMIOLOGY AND TREATMENT OF DRUG-RESISTANT FALCIPARUM MALARIA}

Chloroquine: Following its simultaneous appearance in South America and Southeast Asia in the late 1950s, chloroquine-resistant $\mathrm{P}$ falciparum (CRPF) has spread throughout most of the malaria-endemic world (Table 1). Despite widespread resistance, chloroquine continues to be used as first line treatment for falciparum malaria in much of sub-Saharan Africa. However, chloroquine treatment failed to produce lasting clinical or hematological improvement in falciparuminfected children and it can no longer be considered effective therapy in these areas $(2,20)$. In a recent study from Gabon, cure rates for chloroquine were only $9 \%$, with $47 \%$ of cases demonstrating intermediate or high grade resistance (RII/RIII) 
(21). Of greater concern, however, are increasing reports of quinine treatment failures. In the same study from Gabon, quinine used as monotherapy had only a $32 \%$ cure rate. Combination therapy remains a suitable treatment option and addition of clindamycin to chloroquine improved cure rates in African children to $70 \%(21)$.

Although chloroquine-resistant falciparum malaria has been documented for more than 30 years, the mechanisms of action and resistance to chloroquine have only recently begun to be elucidated. Slater and Cerami (22) demonstrated that chloroquine and other quinoline antimalarials inhibit an essential malarial process responsible for detoxifying hemoglobin breakdown products. In their model a malarial enzyme, heme polymerase, incorporates toxic heme moieties into an insoluble crystalline material called hemozoin or malaria pigment. Chloroquine and quinine inhibit the conversion of heme into hemozoin allowing soluble toxic products to damage parasite membranes and inhibit malarial proteases. More recently, Dorn and colleagues (23) revisited the issue of heme polymerization. Their studies indicate that, while a parasite protein might initiate the polymerization of heme, the majority of the process, rather than being enzyme-mediated, is an autocatalytic chemical event. Their observations do not, however, invalidate the concept of heme polymerization as the site of action of quinoline antimalarials or as a target for new antimalarial drugs.

While chloroquine may exert its antiparasitic effects by inhibiting heme polymerase, resistance to this drug does not appear to be due to mutations in this target. Instead, resistance appears to be mediated by rapid efflux of chloroquine. Drugresistant strains of $P$ falciparum efflux chloroquine 40 to 50 times faster than do chloroquine-sensitive parasites (24). A parasite homologue of the P-glycoprotein responsible for multiple drug resistance (MDR) in mammalian tumour cells has been proposed as the mechanism responsible for rapid efflux resistance in $\mathrm{P}$ falciparum. Supporting this hypothesis, a number of compounds capable of reversing MDR in mammalian cells, including calcium channel blockers, phenothiazines and tricyclic antidepressants, also reverse chloroquine resistance in vitro by inhibiting chloroquine efflux. However, linkage studies have not confirmed this hypothesis and have placed the rapid efflux determinant within a segment of chromosome 7, a region unrelated to P falciparum MDR-like genes (25). Monkey models have been used to examine reversal agents in vivo (26). In these studies, chlorpromazine and prochlorperazine were shown to be the most active compounds, suggesting that structure-function studies of phenothiazines and tricyclic antidepressants might identify useful reversal agents that lack antipsychotic or antidepressant activity. Reversal agents have not yet been shown to be efficacious in treating CRPF infection in humans (27).

In summary, chloroquine is no longer an effective agent for the prevention or treatment of falciparum malaria except in Central America (above Panama), the Caribbean, and in a decreasing region of North Africa and the Middle East. Recent advances in our understanding of the molecular mechanisms of chloroquine action and chloroquine resistance may ulti- mately facilitate the design of new classes of antimalarial agents such as therapeutically useful reversal agents or inhibitors of heme polymerization.

Quinine and quinidine: Quinine and quinidine are cinchona alkaloids derived from the bark of the cinchona tree of South America. Despite 350 years of use, quinine remains an important and effective antimalarial. Quinidine is the dextrorotatary diastereomer of quinine, and as an antimalarial it is intrinsically more active than quinine and more cardiotoxic. Quinine and quinidine are blood schizonticides whose mechanism of action is inhibition of heme polymerization. Both agents rapidly reduce parasitemia, but in most areas of the world they must be combined with a second agent to prevent recrudescence (treatment failure). Resistance to quinine and quinidine is partially reversed in vitro by verapamil, suggesting that rapid efflux mechanisms are involved, at least in part, in mediating resistance. Oral administration is the route of choice for quinine except in cases of severe or complicated malaria or in patients who are vomiting. Since serious cardiovascular toxicity is uncommon with oral or intravenous quinine, cardiac monitoring is generally unnecessary (28). Common side effects include cinchonism, a reversible symptom complex involving tinnitus, nausea, high tone deafness and dysphoria, which occurs in up to $25 \%$ of patients but which is rarely serious enough to necessitate discontinuing therapy. The more serious adverse effects of quinine are hypotension secondary to overly rapid parenteral administration and hypoglycemia secondary to its stimulatory action on the pancreatic beta-cell with resultant hyperinsulinemia. The latter effect is a particular concern for children, pregnant females and patients who remain severely ill for several days. Hyperinsulinemia may be reversed with the somatostatin analogue octreotide. A single $100 \mu \mathrm{g}$ intramuscular dose of octreotide can reverse quinineinduced hypoglycemia for $6 \mathrm{~h}$ (29). Similar adverse effects are noted with quinidine use. However, because quinidine has greater cardiotoxicity cardiac monitoring is recommended.

Parenteral regimens for severe malaria begin with a loading dose, twice that of the maintenance dose, allowing therapeutic concentrations to be reached within hours of initiating treatment. There is no evidence that loading doses convey additional toxicity over conventional regimens (19), and loading dose regimens of quinine produce faster parasite clearance times and better clinical response (28). In severe malaria, quinine and quinidine concentrations tend to peak on the second or third day and fall as the patient recovers. If the patient remains seriously ill, concentrations continue to rise; therefore, parenteral doses should be reduced by one-third to one-half after the second day of treatment (28).

In summary, quinine, when combined with a second agent such as tetracycline or pyrimethamine-sulfadoxine, remains the treatment of choice for CRPF malaria in most endemic areas. However, in Southeast Asia and more recently in Africa, the efficacy of quinine has declined steadily and quinine monotherapy is now associated with a 40 to $70 \%$ failure rate $(21,30)$. A seven-day regimen of quinine plus tetracycline is still satisfactory for treatment of falciparum malaria in Thailand, with approximately 90\% cure rates (31); however, 
increasing recrudescent rates and minimum inhibitory concentrations suggest that failure rates will continue to rise. Furthermore, recent reports from Thailand indicate that quinine treatment for severe malaria is associated with an increasing proportion of patients experiencing prolonged coma and delayed parasite clearance compared with 10 years ago (19). These results highlight the urgent need for new chemotherapeutic agents for severe malaria.

Mefloquine: Mefloquine is a 4-quinolinemethanol available only as an oral formulation. It is a blood schizontocide active against MDR falciparum malaria. Like chloroquine, mefloquine appears to act by inhibition of heme polymerization. Mefloquine is slowly cleared by hepatic biotransformation; its terminal half-life is approximately 20 days. This slow clearance, while an advantage in prophylactic dosing, may have been the major factor facilitating the development of drug resistance. Resistance to mefloquine was first described in Thailand in 1982, and in the past decade in vitro or in vivo resistance has been reported from most other malaria-endemic areas. At present, however, treatment failure with mefloquine is not a significant clinical problem except in regions of Thailand bordering Myanmar (Burma) and Cambodia, where cure rates have fallen from $98 \%$ in 1986 to $71 \%$ in 1990 (16). The mechanism of drug resistance to mefloquine is unknown; however, recent evidence suggests the potential involvement of the $\mathrm{P}$ falciparum MDR gene family. Increased gene copy number and increased gene expression of pfmdr1 have recently been associated with decreased susceptibility to mefloquine and halofantrine (32). An additional concern is the development of cross-resistance between antimalarials. Mefloquine is structurally related to quinine and halofantrine, and recent evidence suggests that mefloquine resistance may drive halofantrine and quinine resistance (33). The development of halofantrine resistance has paralleled that of mefloquine resistance in southeast Thailand (30).

In prophylactic doses, mefloquine is well-tolerated. Adverse effects are similar in frequency and severity to those reported with weekly chloroquine use $(34,35)$. Only about $1 \%$ of mefloquine users have to discontinue prophylaxis because of adverse effects. Children tolerate mefloquine better than adults and, for unclear reasons, men have better tolerance than women (36). Severe neuropsychiatric reactions (psychosis, convulsions) are infrequent with prophylactic doses and occur in approximately one in 10,000 to one in 13,000 individuals, about the same frequency as that reported for chloroquine (34-37). In treatment doses, however, neuropsychiatric reactions are reported to be 10 to 60 times more frequent and are estimated to occur in one in 215 to one in 1700 users at the $15 \mathrm{mg} / \mathrm{kg}$ treatment dosage (34-38). Contraindications to the use of mefloquine are few and include a history or family history of convulsions or major psychiatric disorders. Although mefloquine use is not recommended during pregnancy, recent data indicate that mefloquine is safe and effective for antimalarial prophylaxis or treatment in the second half (more than 20 weeks' gestation) of pregnancy $(37,39)$. Similarly, there is no convincing evidence of teratogenicity or other adverse events during the first half of pregnancy
$(39,40)$. It is recommended that mefloquine not be used with calcium channel blockers, digoxin or beta-blockers, although there is no convincing evidence of adverse interactions with these agents. Mefloquine does, however, increase the QTC prolongation induced by halofantrine, and these two drugs should not be used together.

Since its introduction into clinical trials in 1975, mefloquine has been an effective therapeutic agent against drug-resistant $\mathrm{P}$ falciparum. Increasing the recommended dose of mefloquine from 15 to $25 \mathrm{mg} / \mathrm{kg}$ decreased failure rates from $40 \%$ to $9 \%(36)$. However, this has been at the expense of increased adverse effects and is likely to be only a temporary solution. In an effort to preserve mefloquine efficacy recent therapeutic trials have evaluated drug combinations including mefloquine plus doxycycline or artemisinin derivatives (see below). The combination of mefloquine (25 $\mathrm{mg} / \mathrm{kg}$ ) plus doxycycline (adult dose $200 \mathrm{mg} /$ day for seven days) was effective (cure rates 96\%) and well-tolerated for the treatment of MDR falciparum malaria in Thailand (41).

In summary, mefloquine is an effective and well tolerated drug for malaria chemoprophylaxis in all endemic areas except the Thai-Cambodian and Thai-Myanmar borders. It is more effective than chloroquine plus proguanil for malaria prophylaxis in East and West Africa. At present mefloquine, in treatment doses of $25 \mathrm{mg} / \mathrm{kg}$, is an effective agent against MDR falciparum malaria, although neuropsychiatric adverse effects have limited its use in therapeutic doses, at least in North America. Cross-resistance can be expected to occur among mefloquine, halofantrine and possibly quinine. Unfortunately, the future for mefloquine as a single agent in the treatment of MDR malaria is bleak.

Halofantrine: Halofantrine is a phenanthrene methanol derivative related to mefloquine and quinine. It is more active in vitro than mefloquine and is the most recent addition to the treatment of MDR falciparum malaria. It is available only in an oral formulation, which is limited by variable bio-availability. Absorption is increased when halofantrine is taken with food. Mechanisms of action and resistance to halofantrine are unknown, but may be similar to related compounds such as mefloquine. The main use proposed for halofantrine is in the treatment of mild or moderately severe falciparum malaria, known or suspected to be resistant to chloroquine and possibly to other established antimalarial drugs such as pyrimethamine/sulfadoxine.

Although initial studies of halofantrine showed that doses of $24 \mathrm{mg} / \mathrm{kg}$ (adult dose $500 \mathrm{mg}$ every $6 \mathrm{~h}$ divided into three doses) were effective against $P$ falciparum in Thailand and Africa, more recent studies have not confirmed this. Recent trials from Thailand have reported cure rates of only $65 \%$ to $70 \%$ for primary infections and $40 \%$ in retreatment of recrudescent infections (42). The high recrudescent rate after standard halofantrine therapy has led to the suggestion to retreat patients, particularly nonimmunes, on day 7 . A recent study on the Thai-Myanmar border compared standard dose halofantrine $(24 \mathrm{mg} / \mathrm{kg}$ ) with mefloquine $(25 \mathrm{mg} / \mathrm{kg})$ and a high dose halofantrine regimen $(72 \mathrm{mg} / \mathrm{kg}$ given in doses of $8 \mathrm{mg} / \mathrm{kg}$ every 8 $\mathrm{h}$ for three days). This large study confirmed previous reports 
indicating that standard dose halofantrine is inadequate treatment for MDR falciparum malaria in this area. However, the three-day regimen of halofantrine $(72 \mathrm{mg} / \mathrm{kg}$ ) was better tolerated and more effective than mefloquine $(25 \mathrm{mg} / \mathrm{kg})$, with failure rates of $1 \%$ and $6 \%$, respectively. High dose halofantrine was especially effective in retreatment of recrudescent infections ( $15 \%$ failure rate versus $44 \%$ with mefloquine) (42). However, serious questions were raised about the cardiotoxicity of halofantrine when two patients died during therapy. A subsequent prospective electrocardiographic study of patients treated with high dose halofantrine $(72 \mathrm{mg} / \mathrm{kg}) \mathrm{dem}-$ onstrated consistent dose-related lengthening of the PR and QT intervals in all patients (43). Furthermore, even standard dose halofantrine $(24 \mathrm{mg} / \mathrm{kg})$ is associated with QT prolongation in about $80 \%$ of patients. The likelihood of significant QT prolongation was greater when halofantrine was used as retreatment following mefloquine failure. The World Health Organization (WHO) has reported multiple cardiac deaths associated with the use of halofantrine (44).

Until there is a clearer understanding of the determinants of clinical cardiotoxicity with halofantrine use, established alternatives are preferred in most circumstances. At present the Centers for Disease Control and Prevention, WHO and the Committee to Advise on Tropical Medicine and Travel (CATMAT) recommend that halofantrine should not be used for self-treatment in situations of self-diagnosis of malaria. In addition, halofantrine is not indicated for the treatment of MDR malaria (combined resistance to mefloquine and chloroquine) or for the treatment of recrudescent falciparum malaria. There may be limited use for halofantrine in physician-directed situations where other recommended treatment options are inappropriate or contraindicated. An electrocardiogram should be performed to assess whether there are conduction abnormalities or a prolonged QT interval in individuals who are to receive halofantrine. Halofantrine is contraindicated in patients with congenital or acquired QT interval prolongation and probably should be avoided in patients with severe electrolyte abnormalities, concurrent use of drugs with effects on cardiac conduction, recent prophylaxis or treatment with mefloquine (within four weeks) or quinine, or with thiamine deficiency. If used, the dose should be limited to $24 \mathrm{mg} / \mathrm{kg}$ ( $8 \mathrm{mg} / \mathrm{kg}$ every $6 \mathrm{~h}$ divided into three doses) and repeated at one week. Halofantrine should NOT be taken with food.

Halofantrine is licensed in the United States and Canada, but has not been marketed. It is widely available in Africa and Europe.

Artemisinin (qinghaosu): Artemisinin is a naturally occurring sesquiterpene lactone peroxide, structurally unrelated to any known antimalarial. It was isolated in 1972 from Artemisia annua (wormwood), a plant used by traditional Chinese practitioners since $341 \mathrm{AD}$ for the treatment of fever (45). The first clinical studies of the plant extract in the early $1970 \mathrm{~s}$ showed excellent activity against vivax and falciparum malaria.

Qinghaosu is available as the parent compound artemisinin (oral, parenteral and suppository formulations) and as three semisynthetic derivatives: a water-soluble hemisuccinate salt (artesunate) for parenteral or oral administration; and two oil-soluble compounds, artemether and arteether, for intramuscular injection. Arteether was developed by the WHO for its lipophilic properties, a potential advantage in cerebral malaria, and its presumed less toxic metabolites. Artemisinin suppositories represent an important advance in the treatment of complicated malaria, particularly in rural areas where parenteral therapy is impractical.

Artemisinin compounds are concentrated in parasitized erythrocytes, and their antimalarial activity appears to be mediated, at least in part, by activated oxygen radicals, which form covalent bonds with parasite proteins. Artemisinin compounds act rapidly, and thereby stop parasite development and prevent subsequent cytoadherence and rosetting, two important pathophysiological mechanisms in severe malaria. Qinghaosu and its derivatives have been used in over a million patients and are well-tolerated. There have been no reports of hematological, hepatic or cardiac toxicity in humans. However, recent animal toxicity data indicated that cumulative doses of arteether and artemether were associated with fatal brainstem neurotoxicity in dogs, rats and most recently in primates (46). No clinical neurological events have been described in humans, but no studies have addressed cumulative neurotoxicity in humans. Transient first-degree heart block and liver enzyme elevations have also been described in small numbers of patients. The safety of qinghaosu derivatives in pregnancy has not been established.

Artemisinin compounds are at least as efficacious as quinine in the treatment of severe and complicated malaria. Qinghaosu and its derivatives lead to faster parasite (mean $32 \%$ faster) and fever (mean $17 \%$ faster) clearance times than do any other antimalarials $(47,48)$. One study has recently reported shorter coma resolution times with artemether compared with quinine in Malawian children with cerebral malaria (49). However, it is unknown whether the more rapid antiparasitic action of qinghaosu compounds will decrease mortality associated with severe malaria. Artemisinin-related compounds are rapidly active against drug-resistant $P$ falciparum strains but have high recrudescent rates (approximately 10 to $50 \%$ ) when used as monotherapy (45). Recent studies have examined longer durations of therapy and combinations of qinghaosu derivatives and mefloquine in order to prevent high recrudescent rates. In vitro synergy has been demonstrated among artemisinin derivatives, mefloquine and tetracycline. In Thailand, treatment with oral artesunate $(600 \mathrm{mg}$ over five days) followed by mefloquine $(1250 \mathrm{mg}$ ) was more effective than mefloquine or artesunate alone $(50,51)$. Combination therapy resulted in $100 \%$ cure rates of primary and recrudescent $\mathrm{P}$ falciparum infections. Recent reports indicate that even single-dose artemisinin-mefloquine combinations are efficacious in the treatment of uncomplicated falciparum malaria in Southeast Asia (52). Also promising are new tricyclic trioxanes synthesized as structural analogues of artemisinin. These derivatives have been shown to be many times more potent than artemisinin in vitro and as effective as ar- 
teether against drug-resistant $\mathrm{P}$ falciparum in monkey and rodent models (53).

In summary, qinghaosu derivatives are extremely promising new antimalarial agents. They are gaining a reputation for speed of action even against drug-resistant $\mathrm{P}$ falciparum strains. Although faster parasite and fever clearance have been documented, it is unknown whether these compounds will decrease mortality associated with severe malaria. Combinations of artesunate and mefloquine appear to be the most active drug regimens against MDR falciparum malaria in Southeast Asia. However, present preclinical and toxicity data are insufficient to meet current drug registration requirements necessary for these drugs to be licensed and distributed. There is good evidence that short term therapy with artemisinin compounds is safe; however, questions about long term neurological toxicity require resolution.

Atovaquone: Atovaquone is an oral hydroxynaphthoquinone currently used as an alternative therapy to treat pneumocystis pneumonia and toxoplasmosis encephalitis in AIDS patients. It is also a unique antimalarial that is effective against MDR $P$ falciparum in vitro and in primate malaria models (54). It acts by blocking the respiratory chain at ubiquinone. To date, it has been examined only as a therapeutic agent in malaria. Used as a single agent, atovaquone has unacceptably high recrudescent rates (30\% to $40 \%)$. However, when atovaquone is combined with proguanil or doxycycline, cure rates greater than $90 \%$ were observed against MDR P falciparum (54). Looareesuwan and colleagues (55) recently reporting on phase III trials of MDR falciparum malaria in Thailand found that atovaquone (1000 $\mathrm{mg} /$ day for three days) plus proguanil (400 mg/day for three days) resulted in 100\% cure rates.

New folate antagonists: The future for biguanide compounds, such as proguanil, may lie in a new potent, orally active class of folic acid antagonists such as PS-15. PS-15 is undergoing animal studies and appears to be less toxic than proguanil but considerably more active against multidrugresistant $P$ falciparum (56).

\section{TREATMENT OF DRUG-RESISTANT PLASMODIUM VIVAX}

$P$ vivax is the second most common cause of malaria worldwide and is a frequent cause of imported malaria into nonendemic areas (9). Chloroquine has been the treatment of choice for vivax malaria for over 40 years. Since 1989, cases of vivax malaria failing standard courses of chloroquine have been reported from Papua New Guinea, Irian Jaya, Indonesia, Colombia, and recently from Brazil and Myanmar. Murphy et al (57) have confirmed the presence and high prevalence (greater than $22 \%$ ) of chloroquine-resistant vivax malaria in Irian Jaya. Chloroquine used as a single agent can no longer be relied upon for prophylaxis or treatment of vivax malaria acquired in this geographic region. Few studies have examined alternative drugs for the treatment of vivax malaria. Although effective, quinine is often required in higher doses to cure strains from Papua New Guinea (57). Baird et al (58) recently examined the efficacy of halofantrine and chloroquine plus high dose primaquine for the treatment of chloroquine-resistant $\mathrm{P}$ vivax in Irian Jaya. These studies were based on the observation that primaquine has blood stage antimalarial activity against $\mathrm{P}$ vivax. Standard treatment doses of chloroquine (25 $\mathrm{mg} / \mathrm{kg}$ ) combined with high doses of primaquine, either 2.5 $\mathrm{mg} / \mathrm{kg}$ over $48 \mathrm{~h}$ or $10 \mathrm{mg} / \mathrm{kg}$ over 28 days, had 28-day cure rates of $85 \%$ compared with $22 \%$ for chloroquine alone. Halofantrine alone $(24 \mathrm{mg} / \mathrm{kg})$ was also efficacious with a 28 -day cure rate of $94 \%$.

Relapse of P vivax malaria after standard courses of primaquine (15 mg base/day for 14 days) is also commonly reported from Papua New Guinea, Thailand and other parts of Southeast Asia and Oceania (failure rates approximately $35 \%$ ), and less commonly from India and Colombia. High relapse rates have recently been reported in American soldiers deployed to Somalia (59). Patients who fail a standard course of primaquine should receive either one-and-a-half to two times the standard dose ( 22.5 to $30 \mathrm{mg}$ base/day for 14 days) or the total dose of $6 \mathrm{mg} / \mathrm{kg}$ of primaquine to prevent further relapses.

\section{CONCLUSIONS}

With the resurgence of malaria worldwide, with increasing drug resistance, and with current travel and immigration patterns, the number of cases of drug-resistant malaria imported into Canada will likely continue to rise. To prevent malaria deaths, travellers need to be adequately informed about prevention of malaria using personal protection measures and appropriate chemoprophylaxis and the need to seek prompt medical attention should they develop fever during or after travel.

Because these measures will never be completely protective, physicians must be able to recognize malaria, to order malaria smears on an urgent basis, and to institute prompt and effective therapy in order to prevent malaria-associated morbidity and mortality. The failure of physicians to take a travel history is the major reason for delays in the diagnosis of malaria. Fever in the returned traveller or recent immigrant must be considered to be malaria, and in particular P falciparum, until proven otherwise. When falciparum malaria is suspected, bad outcomes are most often the result of physician misjudgement of the severity and potential complications of this life-threatening infection.

ACKNOWLEDGEMENTS: Supported in part by a grant from PSI and in part by the Ontario Ministry of Health, Career Scientist Award.

\section{REFERENCES}

1. Campbell CC. Challenges facing antimalarial therapy in Africa. J Infect Dis 1991;163:1207-11.

2. Miller L. The challenge of malaria. Science 1992;257:36-7.

3. Malaria. Wkly Epidemiol Rec 1992;67:349-50.

4. Institute of Medicine. Emerging Infections: Microbial Threats to Health in the United States. Washington: National Academy Press, 1992.

5. Bouma MJ, Sondorp HE, van der Kaay HJ. Health and climate change. Lancet 1994;343:302.

6. Loevinsohn ME. Climatic warming and increased malaria incidence in Rwanda. Lancet 1994;343:714-8.

7. Bouma MJ, Sondorp HE, van der Kaay HJ. Climate change and periodic epidemic malaria. Lancet 1994;343:1440. 
8. Molyneux M, Fox R. Diagnosis and treatment of malaria in Britain. BMJ 1993;306:1175-80.

9. Freedman Do. Imported malaria - here to stay. Am J Med 1992;93:239-42.

10. Hoffman SL. Diagnosis, treatment and prevention of malaria. Med Clin North Am 1992;76:1327-55.

11. Malaria surveillance annual summary. Can Dis Wkly Rep 1989;15:199-204.

12. Wittes RC. Recent Canadian deaths from malaria acquired in Africa. Can Dis Wkly Rep 1989;15:199.

13. Winters RA, Murray HW. Malaria - the mime revisited: fifteen more years of experience at a New York City teaching hospital. Am J Med 1992;93:243-6.

14. Kain KC, Tennyson S, Harrington MA, Keystone JS. Imported malaria in Toronto: prospective evaluation of 83 cases over 10 months. Fourth International Conference on Travel Medicine. Acapulco, April 23 to 27, 1995. (Abst 177)

15. Warrell D, Molyneux M, Beales P. Severe and complicated malaria. Trans R Soc Trop Med Hyg 1990;84:1-65.

16. Nosten $\mathrm{F}$, ter Kuile R, Chongsuphajaisiddhi T, et al. Mefloquine-resistant falciparum malaria on the Thai-Burmese border. Lancet 1991;337:1140-3.

17. Brasseur P, Kouamouo J, Moyou RS, et al. Emergence of mefloquine-resistant malaria in Africa without drug pressure. Lancet 1990;336:59.

18. Raccurt CP, Dumestre-Toulet V, Abraham E, et al. Failure of falciparum prophylaxis by mefloquine in travelers from West Africa. Am J Trop Med Hyg 1991;45:319-24.

19. Pukrittayakamee S, Supanaranond W, Looareesuwan S, Vanijanota S, White NJ. Quinine in severe falciparum malaria: evidence of declining efficacy in Thailand. Trans R Soc Trop Med Hyg 1994;88:324-7.

20. Bloland P, Were J, Campbell C. Beyond chloroquine: implications of drug resistance for evaluating malaria therapy efficacy and treatment policy in Africa. J Infect Dis 1993;167:932-7.

21. Kremsner PG, Winkler S, Brandts C, Neifer S, Bienzle U, Graninger W. Clindamycin in combination with chloroquine or quinine is an effective therapy for uncomplicated Plasmodium falciparum malaria in children from Gabon. J Infect Dis 1994;169:467-70.

22. Slater A, Cerami A. Inhibition by chloroquine of a novel haem polymerase enzyme activity in malaria trophozoites. Nature 1992;355:167-9.

23. Dorn A, Stoffel R, Matile H, Bubendorf A, Ridley RG. Malarial haemozoin/beta-haematin supports haem polymerization in the absence of protein. Nature 1995;374:269-71.

24. Krogstad D, Gluzman I, Kyle D, et al. Efflux of chloroquine from Plasmodium falciparum: mechanism of chloroquine resistance. Science 1987;238:1283-5.

25. Krogstad D, Gluzman D, Herwaldt B, Schlesinger P, Wellems T. Energy dependence of chloroquine accumulation and chloroquine efflux in Plasmodium falciparum. Biochem Pharmacol 1992;43:57-62.

26. Kyle D, Milhous W, Rossan R. Reversal of Plasmodium falciparum resistance to chloroquine in panamanian aotus monkeys. Am J Trop Med Hyg 1993;48:126-33.

27. Warsame M, Wernsdorfer W, Bjorkman A. Lack of effect of desipramine on the response to chloroquine of patients with chloroquine-resistant falciparum malaria. Trans $\mathrm{R}$ Soc Trop Med Hyg 1992;86:235-6.

28. White N. Antimalarial pharmacokinetics and treatment regimens. Br J Clin Pharmacol 1992;34:1-10.

29. Phillips R, Looareesuwan S, Molyneux M, Hatz C, Warrel D. Hypoglycemia and counterregulatory hormone responses in severe falciparum malaria: treatment with Sandostatin. Q J Med 1993;86:233-40.

30. Wongsrichanalai C, Webster HK, Wimonwattrawatee T, et al. Emergence of multidrug resistant Plasmodium falciparum in Thailand: in vitro tracking. Am J Trop Med Hyg 1992;47:112-6.

31. Looareesuwan S, Wilairatana P, Vanijanonta S, Kyle D, Webster K. Efficacy of quinine-tetracycline for acute uncomplicated falciparum malaria in Thailand. Lancet 1992;339:369.

32. Wilson C, Volkman S, Thaithong S, et al. Amplification of pfmdr1 associated with mefloquine and halofantrine resistance in Plasmodium falciparum from Thailand. Mol Biochem Parasitol 1993;57:151-60.
33. Peel S, Merritt S, Handy J, Baric R. Derivation of highly mefloquine-resistant lines from Plasmodium falciparum in vitro. Am J Trop Med Hyg 1993;48:385-97.

34. Lobel H, Miani M, Eng T, Bernard K, Hightower A, Campbell C. Long-term malaria prophylaxis with weekly mefloquine. Lancet 1993;341:848-51.

35. Steffen R, Fuchs E, Schildknecht J, et al. Mefloquine compared with other malaria chemoprophylactic regimens in tourists visiting East Africa. Lancet 1993;341:1299-303.

36. ter Kuile F, Nosten F, Thieren M, et al. High-dose mefloquine in the treatment of multidrug-resistant falciparum malaria. J Infect Dis 1992;166:1393-400.

37. White NJ. Mefloquine. BMJ 1994;308:286-7.

38. Weinke T, Trautmann M, Held T, et al. Neuropsychiatric side effects after the use of mefloquine. Am J Trop Med Hyg 1991;45:86-91.

39. Nosten F, ter Kuile F, Maelankiri L, et al. Mefloquine prophylaxis prevents malaria during pregnancy: a double-blind, placebo-controlled study. J Infect Dis 1994;169:595-603.

40. Keystone JS, Kain KC. Mefloquine dangers - fact or fancy? Can J Infect Dis 1995;6:14-5.

41. Looareesuwan S, Viravan C, Vanijanonta P, et al. Randomized trail of mefloquine-doxycycline and artesunate-doxycycline for treatment of acute uncomplicated falciparum malaria. Am J Trop Med Hyg 1994;50:784-9.

42. ter Kuile F, Golan G, Nosten F, et al. Halofantrine versus mefloquine in treatment of multidrug-resistant falciparum malaria. Lancet 1993;341:1044-9.

43. Nosten F, ter Kuile F, Luxemburger C, et al. Cardiac effects of antimalarial treatment of halofantrine. Lancet 1993;341:1054-6.

44. WHO drug alert: halofantrine. Wkly Epidemiol Rec 1993;37:1-2.

45. Klayman D. Qinghaosu (artemisinin): an antimalarial drug from China. Science 1985;228:1049-55.

46. Brewer TG, Peggins JO, Grate SJ, et al. Neurotoxicity in animals due to arteether and artemether. Trans R Soc Trop Med Hyg 1994;88:33-6.

47. Hien T, Arnold K, Vinh H, et al. Comparison of artemisinin suppositories with intravenous artesunate and intravenous quinine in the treatment of cerebral malaria. Trans R Soc Trop Med Hyg 1992:86:582-3.

48. White N, Waller D, Crawley J, et al. Comparison of artemether and chloroquine for severe malaria in Gambian children. Lancet 1992;339:317-21.

49. Taylor T, Wills B, Kazembre P, et al. Rapid coma resolution with artemether in Malawian children with cerebral malaria. Lancet 1993;341:661-2.

50. Looareesuwan S, Kyle D, Virvan C, et al. Treatment of patients with recrudescent falciparum malaria with a sequential combination of artesunate and mefloquine. Am J Trop Med Hyg 1992;47:794-9.

51. Looareesuwan S, Viravan C, Vanijanonta S, et al. Randomised trial of artesunate and mefloquine alone and in sequence for acute uncomplicated falciparum malaria. Lancet 1992;339:821-4.

52. Hien TT, Arnold K, Hung NT, et al. Single-dose artemisininmefloquine treatment for acute uncomplicated falciparum malaria. Trans R Soc Trop Med Hyg 1994;88:688-91.

53. Posner GH, Oh $\mathrm{CH}$, Webster HK, Ager AL, Rosson RN. New, antimalarial, tricyclic 1,2,4-trioxanes: evaluations in mice and monkeys. Am J Trop Med Hyg 1994;50:522-6.

54. Hudson AT, Dickins M, Ginger CD, et al. 566C80: a potent broad spectrum anti-infective agent with activity against malaria and opportunistic infections in AIDS patients. Drugs Exp Clin Res 1991; 17:427-35

55. Looareesuwan S, Viravan C, Webster HK, et al. Clinical studies of atovaquone, alone in or combination with other antimalarial drugs. Am J Trop Med Hyg. (In press)

56. Canfield CJ, Milhous WK, Ager AL, et al. PS-15: a potent, orally active antimalarial from a new class of folic acid antagonists. Am J Trop Med Hyg 1993;49:121-6.

57. Murphy G, Basri H, Purnomo E, et al. Vivax malaria resistant to treatment and prophylaxis with chloroquine. Lancet 1993;341:96-100

58. Baird JK, Basri H, Subianto B, et al. Treatment of chloroquine-resistant Plasmodium vivax with chloroquine and primaquine or halofantrine. J Infect Dis 1995;171:1678-82. 
59. Smoak BL, Defraites RF, Magill AJ, Wellde BT. Malaria among US Army soldiers returning from Operation Restore Hope: Evidence

for primaquine-resistant P. vivax infections. 43rd Annual

Meeting of the American Society of Tropical Medicine and

Hygiene, Cincinnati, November 13 to 17, 1994. (Abst 21)

60. Canadian recommendations for the prevention and treatment of malaria among international travellers. Can Dis Wkly Rep. (In press)

61. Sturchler D, Mittelholzer ML, Kerr L How frequent are notified severe cutaneous adverse reactions to Fansidar? Drug Saf 1993;8:160-8. 


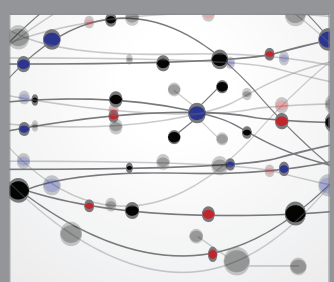

The Scientific World Journal
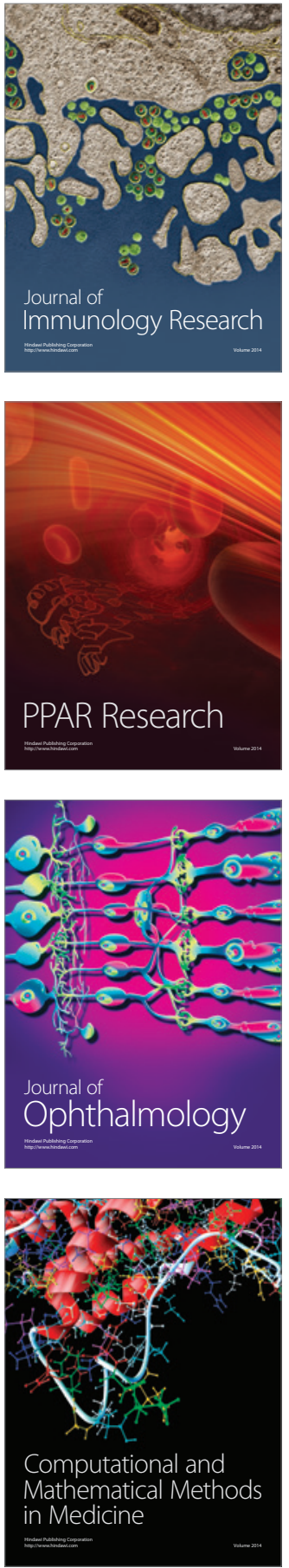

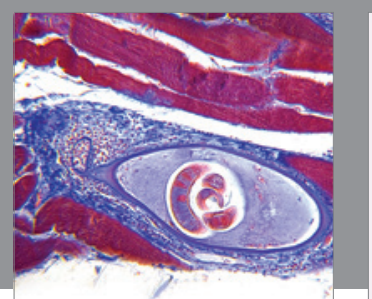

Gastroenterology Research and Practice

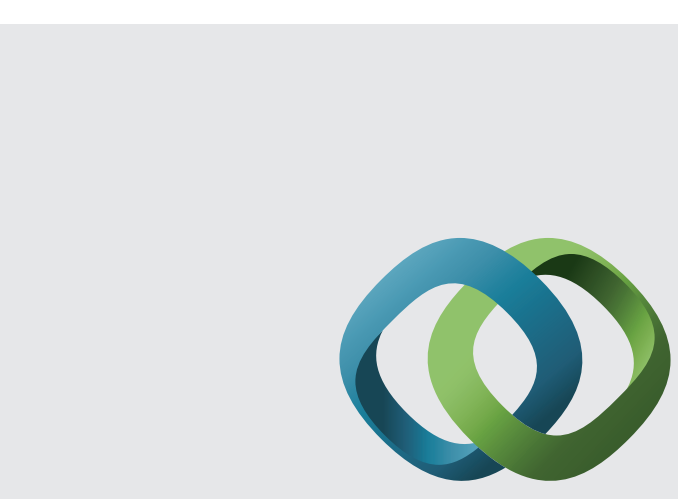

\section{Hindawi}

Submit your manuscripts at

http://www.hindawi.com
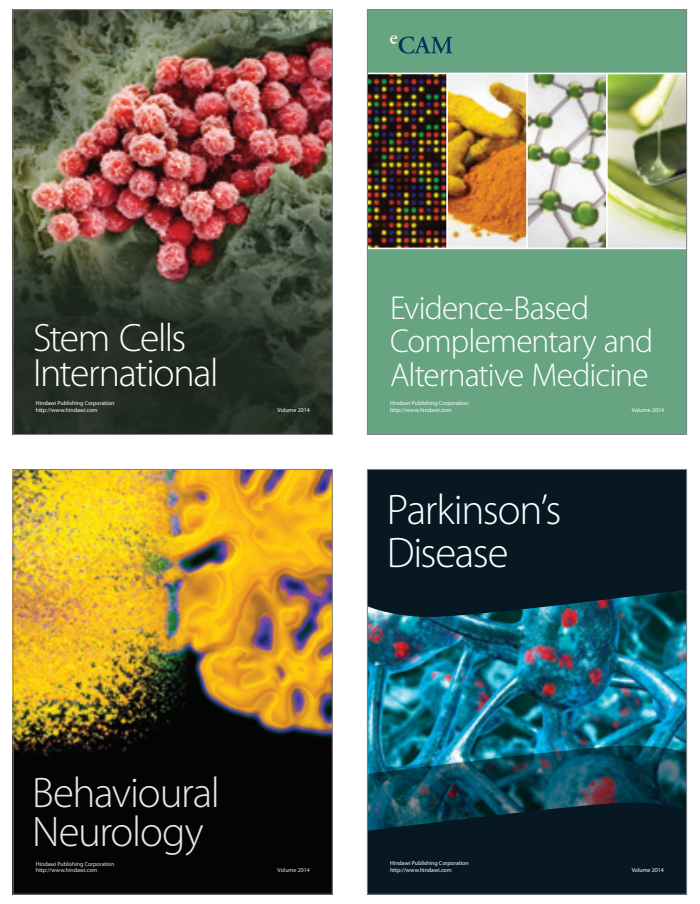
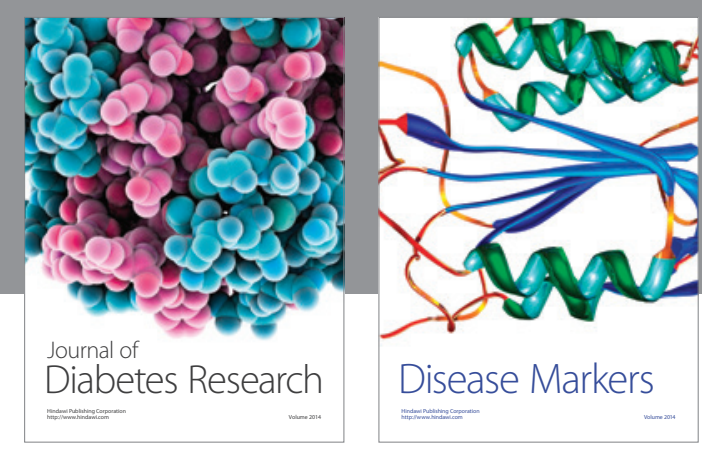

Disease Markers
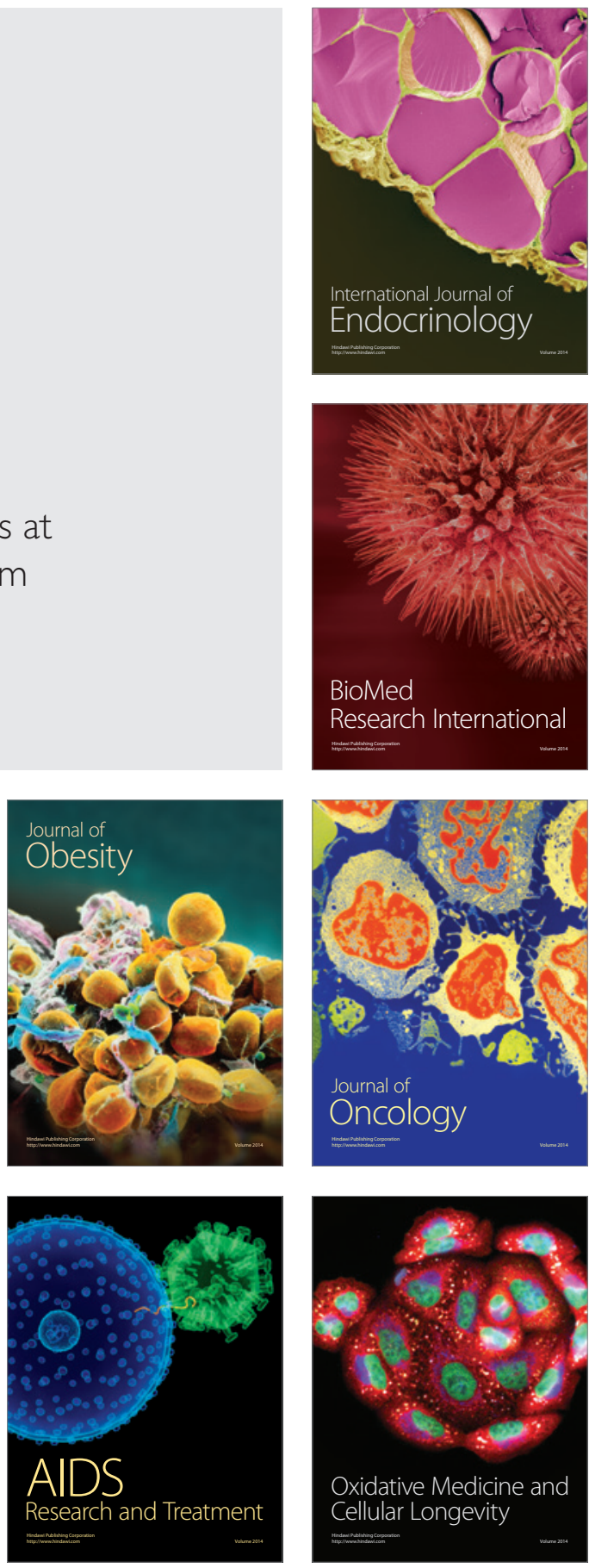